\title{
Prevalence of Depression among Medical Students at Al-Azhar Uni- versity: A Cross Sectional Study
}

\author{
Alaa Abdelwahed Shams-Eldin', Haytham Hassan ${ }^{1 *}$, Omaima Abo Elkhar², Soliman Amer ${ }^{3}$, Khaled Kasim \\ ${ }^{1}$ Department of Community Medicine, Faculty of Medicine for Boys, Al-Azhar University, Cairo, Egypt \\ ${ }^{2}$ Department Community Medicine Faculty of Medicine for Girls, Al-Azhar University, Cairo, Egypt \\ ${ }^{3}$ Department of Community Medicine, Damietta Faculty of Medicine, Al-Azhar University, Damietta, Egypt
}

"Corresponding author: Haytham Hassan, Department of Community Medicine, Faculty of Medicine for Boys, Al-Azhar University, Cairo, Egypt. Tel: +201011342153; Email: drhaytham1972@yahoo.com

Citation: Shams-Eldin AA, Hassan H, Elkhar OA, Amer S, Kasim K (2017) Prevalence of Depression among Medical Students at Al-Azhar University: A Cross Sectional Study. J Community Med Public Health: CMPH-115. DOI: 10.29011/CMPH-115/100015

Received Date: 19 September, 2017; Accepted Date: 06 October, 2017; Published Date: 13 October, 2017

\section{Abstract}

Background: Depression among medical students may prone to develop physical and mental problems. Few studies investigated its prevalence among medical students in Egypt.

Objectives: This study aimed to determine the prevalence of depression and to identify some related risk factors among Al-Azhar University medical students, Cairo, Egypt.

Methods: A cross-sectional study was conducted at faculty of medicine for Boys and Girls, Al-Azhar University, Cairo, Egypt. A cluster sample was taken and included students from all study years. A self-administered questionnaire was completed by 1254 students from January through March 2017. Data concerning socio-demographic and lifestyle and sleeping related factors were collected using a valid self-administered structured questionnaire including PQ-2 instrument for depression screening. The prevalence of depression was estimated, and appropriate statistical analyses were performed to compare the prevalence of depression by the studied students' factors.

Results: The overall prevalence of depression was $42.9 \%$ (95\% CI= 40.3\%-45.7\%). The prevalence was significantly high among female $(46.4 \% \%)$ early study years $(48.4 \%)$, those living away from family. Students reported frequent fast food intake, watching TV and use social media, not in touch with their friends, and those eating one meal per day were also showed significant high prevalence. Sleeping related factors appeared to influence the prevalence of depression among the studied students where prevalence was high among those reported less sleeping hours, use of sleeping medications and those spent $>2$ hours in bed before sleeping.

Conclusion: A high prevalence of depression among the studied medical students was detected. The study suggests a variety of risk factors and the need of psychiatric counseling and support services available to vulnerable students.

Keywords: Al-Azhar; Depression; Egypt; Lifestyle; Medical students; Prevalence

\section{Introduction}

Psychological and mental health problems among university students are considered one of the vital and escalating public health problem worldwide, for which epidemiological data is re- quired and should be addressed as a priority problem [1]. Medical education is among the most challenging and stressful ones [2], and several previous studies

have shown that medical students experience a high level of stress during their undergraduate course [3-7]. High level of stress may have a negative effect on cognitive functioning and learning of students in the medical school [8]. Results of studies suggest 


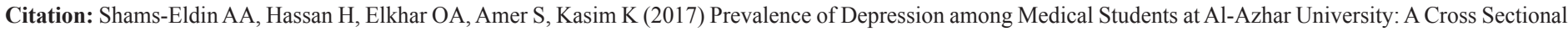
Study. J Community Med Public Health: CMPH-115.

that mental health worsens after students begin medical school and remain poor throughout the training [3].

The studies conducted on medical students in Egypt as well as in different regional countries have shown that medical students have high rates of anxiety \& depression during their years of studying and training. In Egypt, a recent cross-sectional study was carried out on 164 medical students and 164 pharmacy students at Alexandria University. The study reported the prevalence of anxiety and depression among medical students to be $43.9 \%$ and $57.9 \%$, respectively, and the prevalence of anxiety and depression among pharmacy students to be $29.3 \%$ and $51.1 \%$, respectively [9]. Similar results were also obtained regionally, where a cross sectional study conducted on 50 medical students at Faculty of Medicine, King Faisal University, Al Ahsaa region, Saudi Arabia, reported the prevalence of stress among the studied students to be $53 \%$ [10]. In a Meta analysis study, included 35 studies with sample size of 9743, the prevalence of depression among the studied university students was 33\% (95\% CI: 32-34\%), with the prevalence of depression was significantly higher among male students [11].

It is recommended to conduct psychological and mental screening of medical students, as they will be tomorrow's physicians [2]. As anxiety and depression represent the most important health related problems among medical students [1], and as there are great lack of data about the prevalence of these problems among medical students in Egypt, there would be an urgent need to conduct epidemiological study to assess the magnitude of this fundamental problem among medical students at Egyptian Universities. The present study aimed was to determine prevalence depression among male and female medical students at Al-Azhar University, Cairo, Egypt, and to compare students' characteristics by their depression status.

\section{Methods}

A cross section study was conducted to determine the prevalence of depression among medical students at Al-Azhar University, Cairo, Egypt during the study year 2016/17. The medical course at Al-Azhar University consists of two components; the first one is the basic science component, which is the first three years. During this period, students study core medical science, and the other one is the clinical component in the next three years. During this period, the curriculum focuses mainly on clinical subjects and skills. Facilitating the learning process, the students in each study year are classified in groups (sections), and each group including about 100 students.

A cluster sampling procedure was used where only group was randomly chosen from each study year in the studied faculty of medicine for boys and girls. All students from the chosen group in each study year were invited to complete self-administered, anonymous questionnaire during the period from January through March 2017. The questionnaire was designed by the research team and it was based on PQ-2 for depression screening questions [1214]. The questionnaire has also included socio-demographic and data related to dietary habit and other lifestyle factors. Sleeping related variables and associated chronic medical problems ware also included in the study questionnaire. The PQ-2 is an ultra-short screening instruments, including simple questions inquiring about the frequency of depressed mode and anhedonia over the past two weeks and, and include only the first two items from PHQ-9. The question was as follow: over the past 2 weeks, how often have you bothered by any of the following statements; i) little interest or pleasure in doing things, ii) Feeling down, depressed or hopeless. The PQ-2 score ranges from 0-6 where score 0 indicates "Not at all", score 1 "Several days", 2 "More than half the days", 3 "Nearly every day". The cutoff score of 3 was used as the optimal cutoff point in this study for screening purpose. It is mentioned that cutoff score of 3 would enhance the sensitivity of PQ-2 questionnaire and improve its specificity [13]. The validity of other variables included in the study questionnaire was tested by a psychiatrist and an epidemiologist.

The calculated sample size of this study was 1230 students based on the average estimated depression prevalence among medical students in the previous Egyptian studies (54\%) done in the faculty of medicine at Alexandria University [9], an assumed precision of $3 \%$ and a confidence interval of $95 \%$.

The questionnaires were completed and returned back by 1254 students at faculty of medicine for boys and girls during the study year $2016 / 17$. The back $\neg$ ground and purpose of the study were explained at the beginning of the questionnaire.

The collected data were entered and analyzed using SPSS package (version 19.0). Data was presented using frequencies. The prevalence of depression among the studied students was assessed and its $95 \%$ confidence interval was calculated. The prevalence of depression was then compared by all studied students' characteristics using chi square test. P values $\leq 0.05$ were used as indicators of statistical significance differences between the studied groups. The participation of students was voluntary and ethical considerations were also considered to ensure confidentiality and privacy of the collected data. Finally, approval was taken from the ethics committee at Al-Azhar Faculty of Medicine.

\section{Results}

The overall prevalence rate of depression among the studied 1254 medical students at Al-Azhar University was $42.9 \%$ (95\% $\mathrm{CI}=40.3 \%-45.7 \%)$. Table 1 


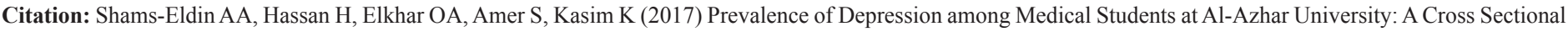
Study. J Community Med Public Health: CMPH-115.

\begin{tabular}{|c|c|c|c|}
\hline \multirow{2}{*}{$\begin{array}{c}\text { Socio-demographic } \\
\text { factors* }\end{array}$} & \multicolumn{2}{|c|}{ Depression } & \multirow[b]{2}{*}{$P$ value } \\
\hline & $\begin{array}{c}\text { Yes } \\
(n=539)\end{array}$ & $\begin{array}{c}\text { No } \\
(n=715)\end{array}$ & \\
\hline \multirow{3}{*}{$\begin{array}{c}\text { Sex } \\
\text { Male }(n=623) \\
\text { Female }(n=631)\end{array}$} & & & \multirow[b]{3}{*}{$0.01 * *$} \\
\hline & $246(39.5)$ & $377(59.5)$ & \\
\hline & $293(46.4)$ & $338(53.6)$ & \\
\hline \multirow{3}{*}{$\begin{array}{c}\text { Study year } \\
\text { Basic sciences study } \\
\text { years } \\
\text { Clinical sciences } \\
\text { study year }\end{array}$} & & & \multirow[b]{3}{*}{$<.0001 * *$} \\
\hline & $323(48.4)$ & $344(51.6)$ & \\
\hline & $216(36.8)$ & $371(63.2)$ & \\
\hline \multirow{4}{*}{$\begin{array}{c}\text { Residence } \\
\text { University residence } \\
\text { Outside university } \\
\text { residence } \\
\text { With the family }\end{array}$} & & & \multirow[b]{4}{*}{$0.01 *$} \\
\hline & $340(442)$ & $430(558)$ & \\
\hline & $162(44.8)$ & $200(55.2)$ & \\
\hline & $37(30.3)$ & $85(69.7)$ & \\
\hline
\end{tabular}

Table 1: Prevalence of depression by socio-demographic data of the studied medical students.

Presents the prevalence of depression among the studied students by their socio-demographic factors. The depression was significantly more prevalent among female students $(46.4 \%$ among females vs. $39.5 \%$ among males). The prevalence of depression was significantly higher among basic sciences level students (1st, 2nd and 3rd study years) compared to clinical sciences level students $\left(4^{\text {th }}, 5^{\text {th }}\right.$ and $6^{\text {th }}$ study years) where the prevalence was $48.4 \%$ and $36.8 \%$, respectively. A significant low level of depression, however, was found among students who reported living with their family $(30.3 \%)$ compared to those reported living in University residence $(44.2 \%)$ and outside residence but without their families (44.8\%). Table 2

\begin{tabular}{|c|c|c|c|}
\hline \multirow{2}{*}{ Lifestyle factors* } & \multicolumn{2}{|c|}{ Depression } & \multirow{2}{*}{ P value } \\
\cline { 2 - 3 } & Yes (n= 539) & No (n= 715) & \\
\hline Smoking & & & \\
Non smokers & $527(42.9)$ & $700(57.1)$ & \\
Smokers & $12(44.4)$ & $15(55.6)$ & 0.87 \\
\hline Physical activity per & & & \\
week & $301(43.3)$ & $393(56.7)$ & \\
No & $144(44.2)$ & $182(55.8)$ & \multirow{2}{*}{0.75} \\
$<3$ sessions & $68(39.3)$ & $105(60.7)$ & \\
$3-5$ sessions & $26(42.6)$ & $35(57.4)$ & \\
$>5$ sessions & & & \\
\hline
\end{tabular}

\begin{tabular}{|c|c|c|c|}
\hline $\begin{array}{l}\text { Fast food per week } \\
\qquad \begin{array}{c}\text { No } \\
1-3 \\
3-5 \\
>5\end{array}\end{array}$ & $\begin{array}{c}182(37.7) \\
253(44.8) \\
68(48.9) \\
36(52.9)\end{array}$ & $\begin{array}{l}300(62.3) \\
312(55.2) \\
71(51.1) \\
32(47.1)\end{array}$ & $0.01 * *$ \\
\hline $\begin{array}{l}\text { Soft drink per week } \\
\qquad \begin{array}{c}\text { No } \\
1-3 \\
3-5 \\
>5\end{array}\end{array}$ & $\begin{array}{l}174(45.9) \\
227(42.4) \\
85(40.1) \\
53(41.1)\end{array}$ & $\begin{array}{l}205(54.1) \\
308(57.6) \\
127(59.9) \\
75(58.9)\end{array}$ & 0.52 \\
\hline $\begin{array}{c}\text { Number of meals } \\
\text { per day } \\
1 \\
2 \\
3 \\
>3\end{array}$ & $\begin{array}{c}15(57.6) \\
245(46.1) \\
231(38.4) \\
48(50.0)\end{array}$ & $\begin{array}{c}11(42.4) \\
286(53.9) \\
370(61.6) \\
48(50.0)\end{array}$ & $0.01 * *$ \\
\hline $\begin{array}{l}\text { T.V. watching and/ } \\
\text { or Social media time } \\
\text { per day } \\
\text { No } \\
<2 \text { hours } \\
2-4 \text { hours } \\
>4 \text { hours }\end{array}$ & $\begin{array}{l}130(45.8) \\
160(37.7) \\
140(42.3) \\
109(50.7)\end{array}$ & $\begin{array}{l}154(54.2) \\
264(62.3) \\
191(57.7) \\
106(49.3)\end{array}$ & $0.01 * *$ \\
\hline $\begin{array}{l}\text { Keeping in touch } \\
\text { with friends outside } \\
\text { medical school } \\
\text { Never } \\
\text { Rarely } \\
\text { Often } \\
\text { Most of time }\end{array}$ & $\begin{array}{c}41(53.3) \\
223(47.6) \\
186(35.9) \\
89(46.3)\end{array}$ & $\begin{array}{l}36(46.7) \\
245(52.4) \\
331(64.1) \\
103(53.7)\end{array}$ & $0.0003 * *$ \\
\hline $\begin{array}{c}\text { Stimulant drugs } \\
\text { intake } \\
\text { No } \\
\text { Yes }\end{array}$ & $\begin{array}{c}505(42.8) \\
34(44.7)\end{array}$ & $\begin{array}{c}673(57.2) \\
42(55.3)\end{array}$ & 0.75 \\
\hline $\begin{array}{c}\text { BMI }\left(\mathrm{kg} / \mathrm{m}^{2}\right) \\
<25 \\
25-<30 \\
\geq 30\end{array}$ & $\begin{array}{l}348(42.6) \\
154(42.5) \\
37(48.9)\end{array}$ & $\begin{array}{c}468(57.4) \\
208(57.5) \\
39(51.1)\end{array}$ & 0.54 \\
\hline & $\begin{array}{l}\text { are presen } \\
* * \text { Signif }\end{array}$ & $\mathrm{n}(\%)$ & \\
\hline
\end{tabular}

Table 2: Comparison between depressed and non-depressed students according to life-style factors.

Displayed the comparison between depressed and no de- 


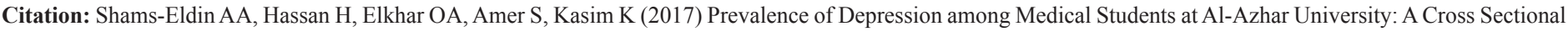
Study. J Community Med Public Health: CMPH-115.

pressed students according to their lifestyle factors. There were no statistically significant differences between depressed and non-depressed students in matters of smoking status and physical activity practice, although the prevalence of depression was slightly higher among smokers and

those with no or less physical activity practice. On the other hand, however, there were statistically significant differences regarding the number of the number of weekly and daily number of meals where the higher proportion of the depressed students was among those reported eating more than 5 fast food per week $(52.9 \%)$ and to eat only one food meal per day (57.6\%). The prevalence of depression was significantly higher among those with no contact with friends outside $(53.3 \%)$ and those who spent more time watching TV (50.7\%).

The prevalence of depression among the studied students, however, showed no significant variations by their body mass index. The prevalence of depression was $45.6 \%$ and $45.6 \%$ among normal weight and overweight students while it was slightly higher (48.9\%) among obese students. Table 3

\begin{tabular}{|c|c|c|c|}
\hline \multirow[b]{2}{*}{ Sleep habit factors* } & \multicolumn{2}{|c|}{ Depression } & \multirow[b]{2}{*}{ P value } \\
\hline & $\begin{array}{c}\text { Yes } \\
(n=539)\end{array}$ & $\begin{array}{c}\text { No } \\
(n=715)\end{array}$ & \\
\hline $\begin{array}{l}\text { Sleeping duration } \\
\text { per day } \\
<6 \text { hours } \\
6-8 \text { hours } \\
>8 \text { hours }\end{array}$ & $\begin{array}{c}97(47.1) \\
312(39.9) \\
130(48.2)\end{array}$ & $\begin{array}{l}105(52.9) \\
470(60.1) \\
140(51.8)\end{array}$ & $0.02 * *$ \\
\hline $\begin{array}{c}\text { Time spent in bed } \\
\text { before sleeping } \\
<1 \text { hour } \\
1-2 \text { hours } \\
>2 \text { hours }\end{array}$ & $\begin{array}{c}328(38.7) \\
163(31.8) \\
48(52.2)\end{array}$ & $\begin{array}{c}519(61.3) \\
152(68.2) \\
44(47.8)\end{array}$ & $<.0001 * *$ \\
\hline $\begin{array}{c}\text { Taking sleeping } \\
\text { medication } \\
\text { Never } \\
\text { Rarely } \\
\text { Often }\end{array}$ & $\begin{array}{c}486(43.2) \\
41(39.1) \\
12(52.2)\end{array}$ & $\begin{array}{c}640(56.8) \\
64(60.9) \\
11(47.8)\end{array}$ & 0.47 \\
\hline & $\begin{array}{l}\text { are prese } \\
* * \text { Sign }\end{array}$ & n $(\%)$ & \\
\hline
\end{tabular}

Table 3: Comparison between depressed and non-depressed students according to sleep habit.

Showed the comparison between depressed and non-depressed students according to their sleeping related factors the prevalence of depression showed statistically significant difference by sleeping duration a day where the prevalence was $47.1 \%$ and $48.2 \%$, respectively, among students reported to sleep $<6$ hours and $>8$ hours a day. Time spent in bed before sleeping was also showed significant high depression prevalence among report to spend more than 2 hours $(52.2 \%)$. Students reported to often taking sleeping medications showed a non-significant high depression prevalence of depression of $52.2 \%$. Table 4

\begin{tabular}{|c|c|c|c|}
\hline \multirow[b]{2}{*}{ Sleep habit factors* } & \multicolumn{2}{|c|}{ Depression } & \multirow[b]{2}{*}{ P value } \\
\hline & $\begin{array}{c}\text { Yes } \\
(n=539)\end{array}$ & $\begin{array}{c}\text { No } \\
(n=715)\end{array}$ & \\
\hline $\begin{array}{c}\text { Study hours/day } \\
<2 \\
2-4 \\
>4\end{array}$ & $\begin{array}{l}71(39.1) \\
255(45.8) \\
213(41.3)\end{array}$ & $\begin{array}{l}111(60.9) \\
301(54.2) \\
303(58.7)\end{array}$ & 0.23 \\
\hline $\begin{array}{l}\text { Study state } \\
\text { Self-study all the time } \\
\text { Mostly self-study } \\
\text { In a group all the time } \\
\text { Mostly in a group study }\end{array}$ & $\begin{array}{l}241(44.7) \\
263(41.9) \\
10(28.5) \\
25(48.1)\end{array}$ & $\begin{array}{l}298(55.3) \\
365(59.1) \\
25(71.5) \\
27(51.9)\end{array}$ & 0.21 \\
\hline $\begin{array}{c}\text { Study limits social life } \\
\text { Yes } \\
\text { No }\end{array}$ & $\begin{array}{l}380(48.3) \\
159(34.1)\end{array}$ & $\begin{array}{l}407(51.7) \\
308(65.9)\end{array}$ & $<.0001 * *$ \\
\hline $\begin{array}{l}\text { Last year academic } \\
\text { grades*** } \\
\text { Acceptable } \\
\text { Good } \\
\text { Very good } \\
\text { Excellent }\end{array}$ & $\begin{array}{l}27(43.5) \\
78(36.5) \\
183(44.8) \\
160(43.1)\end{array}$ & $\begin{array}{l}35(56.5) \\
136(63.5) \\
225(54.2) \\
212(56.9)\end{array}$ & 0.24 \\
\hline $\begin{array}{l}* \text { Data } \\
* * * \text { The analyses were do } \\
1^{\text {st }} \mathrm{y}\end{array}$ & $\begin{array}{l}\text { presented } \\
* \text { Significan } \\
\text { for only } 105 \\
\text { were not in }\end{array}$ & $\begin{array}{l}\mathrm{n}(\%) \\
\text { tudents as } \mathrm{s} \\
\text { ided }\end{array}$ & ents of the \\
\hline
\end{tabular}

Table 4: Comparison between depressed and non-depressed students according to study related factor.

Presented the prevalence of depression among the studied students according to their study related variables The prevalence of depression among the studied students did not show significant difference by students' study hours per day, studying all the time in a group although the prevalence of depression was lower among those reported to study less than two hours a day $(39.1 \%)$ and those studying all the time in a group (28.5\%). A significant higher depression rate was found among students reported that study limits social life $(\mathrm{p}<0.001)$ with a prevalence rate of depression was $48.3 \%$ The prevalence of depression among the studied students showed no statistically significant difference by their academic grades, although the prevalence of depression was found to be the highest among students with very good academic grade $(44.8 \%)$ and to be the lowest among students with good academic grade $(36.5 \%)$.

\section{Discussion}

The present study revealed a high prevalence of depression among medical students at Al-Azhar University in Cairo, Egypt. The estimated prevalence was $42.9 \%(95 \% \mathrm{CI}=40.3 \%-45.7 \%)$. 


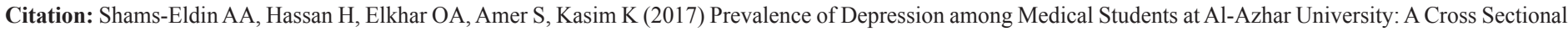
Study. J Community Med Public Health: CMPH-115.

A much higher prevalence was reported in the previous Egyptian study conducted in Alexandria on the medical and pharmaceutical students where the prevalence of depression among the studied students was $57 \%$ and $51 \%$, respectively [9]. Regionally, a high prevalence of anxiety and depression was also reported among medical students in two Saudi studies. One of these two studies reported the prevalence of stress among medical students at King Faisal University to be 53\% [10]. In the other study, conducted on 775 medical students of College of Medicine, King Saud University in Riyadh city, the prevalence of depression was $63 \%$ [15]. The higher prevalence of depression among medical students has been explained by several theories in many researches. Some have contributed these findings to that medical students pass through continuous examinations throughout their academic years. Studying medicine is competitive. Several academic stressors were reported in many previous researches [16].

The prevalence of depression among medical students in this study showed significant variations by sex, study years and residence of the students. The prevalence was significantly high among female students (46.4\%), basic sciences study year students (29.6\%), and among students who reported living in (44.2\%) and outside the university residence (48.4\%) away from their families. In Alexandria study, the prevalence of depression and stress was higher among the female students [9]. Also, in a recent cross-sectional study conducted on 450 female medical students in King Abdulaziz University, Jeddah, Saudi Arabia, the prevalence of depression was $36.5 \%$; while $21.8 \%$ and $14.7 \%$ had a border-line and morbid depression, respectively [17]. Other studies conducted Australia [18] and Finland [19], however, have shown that the gender differences in specific stress symptoms and overall prevalence or mean scores of stresses were scarce and did not turn out to be a significant factor in reporting of stress.

Living away from families may be considered as a contributing factor in of increased prevalence of depression among female, as the study results revealed that students away from their family (In and outside the University Residence) were found to have had a significant high prevalence of depression. The proportion of students reported living away from the family was significantly higher in female compared to male students in this study (It Was 92.3\% Among Females Vs. 85.2\% Among Males). These findings appeared consistent with the results of South Korean study reported high depression prevalence among students living alone at a lodging house or a rented room, unmarried students, and among students with financial difficulty [20].

An interesting finding of the present study was that the level of depression decreased as the year of study progressed. The level of depression in this study was found to increase among students in the first three years of the medical course (basic sciences course). Among these students the prevalence was $48.4 \%$ compared to only $36.8 \%$ among clinical sciences study years students. These findings have also been documented in other studies $[12,19]$.This is contradictory to the finding of another study where the level of stress increased progressively during the course, to reach as high as $40 \%$ by the end of the clinical training period [21]. Results of other studies in North America, however, suggest that mental health worsens after students join a medical school and remains poor throughout the course [22], especially in the transition from basic science teaching to clinical training [23].These contradictions could be attributed to the nature of the present and other similar studies as they were cross-sectional and not cohort studies to be sure that the stress is really decreasing in the study subjects.

The comparison of depression prevalence among medical students in this study by their lifestyle characteristics showed significant variations for some studied factors. The prevalence was significantly high among students reported frequent weekly intake of fast food for $>5$ times $(52.9 \%)$, eating only one meal per day where the $(50.0 \%)$, among those watching TV and/or on social media for $>4$ hours a day $(50.7 \%)$, and among those never kept in touch with friends outside medical school (53.3\%). Consistent with these findings, bad dietary habits, were found in many studies to be associated with increased risk of mental and psychological disturbance, particularly among adolescents [24-26]. Also, the prevalence of depression in this study was higher among smokers (44.4\%), stimulant drugs consumers (44.7\%), and obese students (48.9\%), although not significant. These findings contribute to the evidence suggests that individuals with increased anxiety are more likely to be obese and smoke $[27,28]$. Stimulant drug intake and consuming energy drinks were considered in previous studies as important risk factors for anxiety and depression [24,29].

The prevalence of depression among the studied students was significantly higher among those reported sleeping disorders. Students reported sleeping $<6$ hours and $>8$ hours a day, spent for $>2$ hours in bed before sleeping and those taking sleeping medication showed a significant high level of depression compared to other students where the prevalence was $47.1 \%$ and $48.2 \%, 52.2 \%$, $52.2 \%$, respectively. Sleep disturbances commonly are associated with many psychologic disorders including anxiety disorders, and depression, and sleep loss may exacerbate and contribute to relapse of these conditions [30-33].

The study findings revealed varying level of depression among the studied students according to their study related factors. The prevalence was relatively low among students studying in a group all the time (28.5\%), those reported that studying does not limit their social activity (34.1\%), and among those studying less than 2 hour per day (39.1\%). Unexpectedly, the depression level was high among students with high grade scores as it was $44.8 \%$ and $43.1 \%$ among those with very good and excellent grades, respectively. On contrary to this unexpected finding, it has 


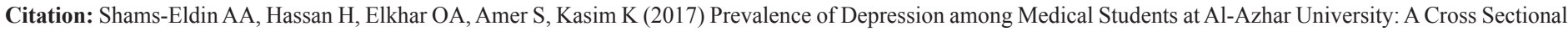
Study. J Community Med Public Health: CMPH-115.

been found that students who had moderate and high performance in examination were less likely to develop depression compared to those who had low performance $[11,12]$. This aspect is difficult to explain based on the

findings of the study. It is possible that students with high academic grades are always in stress to keep their high performance and academic achievement and to engage the specific specialty, they want, later on after their graduation-both are possible.

The strengths of the present study include that the used study questionnaire was comprehensive and based on a simple and valid PQ-2 instrument for depression screening. To the best of the available knowledge, this study is the first to screen for depression among medical students at Al-Azhar faculty of medicine in both boys and girls campuses medicine. Compared to previous local and regional similar studies, the current study included a relatively large sample size. The high response rate among the chosen groups in this study $(96.5 \%)$ consolidated the study findings. Moreover, this study has compared the prevalence of depression among the studied students by several groups of risk factors; including sociodemographic, lifestyle, sleeping related, and study related factors. Some of these factors were not previously touched in other similar local and regional studies.

This study has also number of limitations. Self-selection and information bias may have been a limitation factor in this study. However, because of the high response rate and the anonymous and self-administered distribution of the study questionnaire have greatly minimized the bias expected from the fear of stigma. The use of simple two questions (PQ-2) for depression screening in this study may the validity of this instrument. However, the use of cutoff of 3 (0-6 scores) is known to enhance sensitivity and improve specificity of this instrument. The reliability studies have documented the validity of PQ-2 and PQ-4 as ultra-brief measures of depression and anxiety not only among students but also in the general population $[13,14]$. Furthermore, because of high prevalence of depression among medical students reported in previous studies would increase the positive predictive value of the instrument. Finally, being a cross-sectional design and including only medical, that future research will need to include students from other health related faculties such as faculty of pharmacy, dentistry and nursing to assess the extent of the problem in students affiliated to different health related faculties.

In conclusion, the prevalence of depression was high, particularly among females, living away from families and early study years students. The study hypothesized several risk factors to influence the occurrence of this problem among the studied medical students. Among these factors, residence and social status and dietary habits play great role. Also, the study and sleeping related factors were appeared to influence the prevalence in the studied students. Addressing these results at faculty level may help to in- crease awareness of students and faculty administrators about this health problem. Also, the findings of study may encourage more researchers to take this important topic into their consideration studying it on large scale in well-designed longitudinal study with the aim to develop effective preventive and counseling services for the students.

\section{Acknowledgements}

The authors would like to thank students who participated in this study. The authors also acknowledge the role of Dr. Khairy Abdel-Hamid, Dr. Gamal Abo Sheishaa, Dr. Saad Kandeil and Dr. Ahmed Saba during the process of data collection.

\section{Conflict of interest}

The authors declare that there have no competing interests and that they have not received any grants for this study.

\section{References}

1. Eisenberg D, Hunt J, Speer N (2013) mental health in American colleges and universities: variation across student. J Nerv Ment Dis 201: 60-67.

2. Mancevska S, Bozinovska L, Tecce J, Pluncevik-Gligoroska J, Sivevska-Smilevska E (2008) Depression, anxiety and substance use in medical students in the Republic of Macedonia. Bratisl Lek Listy109: 568-572.

3. Rosal MC, Ockene IS, Ockene JK, Barrett SV, Ma Y et al. (1997) A longitudinal study of students' depression at one medical college. Acad Med 72: 542-546.

4. Stewart SM, Lam TH, Betson CL, Wong CM, Wong AM (1999) A prospective analysis of stress and academic performance in the first two years of medical school. Med Educ 33: 243-250.

5. Singh G, Hankins M, Weinman JA (2004) Does medical school cause health anxiety and worry in medical students? Med Educ 38: 479-481.

6. Wilkinsos TJ, Gill DJ, Fitzjohn J, Palmer CL, Mulder RT (2006) the impact on students of adverse experiences during medical school. Med Teach 28: 129-135.

7. Styles WM (1993) Stress in undergraduate medical education: 'the mask of relaxed brilliance' $\mathrm{Br} \mathrm{J}$ Gen Pract 43: 46-47.

8. Dahlin M, Joneborg N, Runeson B (2005) Stress and depression among medical students: a cross-sectional study. Med Educ 39: 594604.

9. Ibrahim MB, Abdelreheem MH (2015) Prevalence of anxiety and depression among medical pharmaceutical students in Alexandria University (2014). Alexandria J Med 51: 167-173.

10. Abdel Rahman AG, Al Hashim BN, Al Hiji NK, Al-Abbad Z (2013) Stress among medical Saudi students at College of Medicine, King Faisal University J Prev Med Hyg 54: 195-199.

11. Sarokhani D, Delpisheh A, Veisani Y, Sarokhani MT, Manesh RE, et al. (2013) Prevalence of Depression among University Students: A Systematic Review and Meta-Analysis Study. Depression Research and Treatment 2013: 373857. 
Citation: Shams-Eldin AA, Hassan H, Elkhar OA, Amer S, Kasim K (2017) Prevalence of Depression among Medical Students at Al-Azhar University: A Cross Sectional Study. J Community Med Public Health: CMPH-115.

12. Maurer DM (2012) screening for depression. Is Fam Physician 85: 139-144.

13. Kroenke K, Spitzer RL, Williams JB (2003) the patient Health questionnaire-2: validity of a two-item depression screener. Medical care 41:1284-1294

14. Löwe B, Wahl I, Rose M, Spitzer C, Glaesmer H, et al. (2010) A 4-item measure of depression and anxiety: validation and standardization of the Patient Health Questionnaire-4 (PHQ-4) in the general population. J Affect Disord 122: 86-95.

15. Abdulghani HM, AlKanhal AA, Mahmoud ES, Ponnamperuma GG, Alfaris EA (2011) Stress and Its Effects on Medical Students: A Crosssectional Study at a College of Medicine in Saudi Arabia. Journal of Health, Population, and Nutrition 29: 516-522.

16. Mikolajczyk R, Maxwell A, El Ansari W, Naydenova V, Stock C (2008) Prevalence of depressive symptoms in university students from Germany, Denmark, Poland and Bulgaria. Soc Psychiatry Psychiatr Epidemiol 43: 105-112.

17. Ibrahim N, Al-Kharboush D, El-Khatib L, Al-Aabib A, Asali D. (2013) Prevalence and Predictors of Anxiety and Depression among Female Medical Students in King Abdulaziz University, Jeddah, Saudi Arabia. Iran J Public Health 42: 726-736.

18. Kilkkinen A, Kao-Philpot A, O'Neil A, Philpot B, Reddy P, et al. (2007) Prevalence of psychological distress, anxiety and depression in rural communities in Australia. Aust J Rural Health 15: 114-119.

19. Niemi PM, Vainiomaki PT (2006) Medical students' distress-quality, continuity and gender differences during a six-year medical programme. Med Teach 28: 136-141.

20. Myoung-Sun R, Sung KH (2010) The Prevalence and Impact of Depression Among Medical Students: A Nationwide Cross-Sectional Study in South Korea. Academic Medicine 85: 1384-1390.

21. Dyrbye L, Thomas MR, Shanafelt TD (2005) Medical student distress: causes, consequences, and proposed solutions. Mayo Clin Proc 80: 1613-1622.
22. Helmers KF, Danoff D, Steinert Y, Leyton M, Young SN (1997) Stress and depressed mood in medical students, law students, and graduate students at McGill University. Acad Med 72: 708-714.

23. Guthire E, Black D, Bagalkote H, Shaw C, Campbell M, et al. (1998) Psychological stress burnout in medical students: a five-year prospective longitudinal study. J R Soc Med 91: 237-243.

24. Berigan T (2005) An Anxiety Disorder Secondary to Energy Drinks. Psychiatry (Edgmont) 2: 10.

25. Guilbeau JR (2012) Health risks of energy drinks: what nurses and consumers need to know. Nurs Women's Health 16: 423-428.

26. Sepkowitz KA (2013) Energy drinks and caffeine-related adverse effects. JAMA 309: 243-244.

27. Goodwin RD, Lewinsohn PM, Seeley JR (2005) Cigarette smoking and panic attacks among young adults in the community: the role of parental smoking and anxiety disorders. Biol. Psychiatry 58: 686-693.

28. Cuijpers P, Smit F, ten Have M, de Graaf R (2007) Smoking is associated with first-ever incidence of mental disorders: a prospective population-based study. Addiction 102: 1303-1309.

29. Salmons PH (1983) Psychiatric illness in medical students. Br J Psychiatry 143: 505-508.

30. Papadimitriou GN, Linkowski P (2005) Sleep disturbance in anxiety disorders. Int Rev Psychiatry 17: 229-236.

31. Mellman TA (2006) Sleep and anxiety disorders. Psychiatr Clin North Am 29: 1047-1058.

32. Uhde TW, Cortese BM, Vedeniapin A (2009) Anxiety and sleep problems: emerging concepts and theoretical treatment implications. Curr Psychiatry Rep 11: 269-276.

33. Reteguiz J-A (200) Relationship between Anxiety and Standardized Patient Test Performance in the Medicine Clerkship. Journal of General Internal Medicine 21: 415-418. 